\title{
Decyl Heptadecanoate Detected in Ethyl Acetae Leaf Extract of Chrysophyllum albidium
}

\author{
Ushie O.A*1, Adamu, H.M. ${ }^{2}$, Chindo, I.Y. ${ }^{2}$ and Jonnes, B.B ${ }^{3}$ \\ ${ }^{1}$ Department of Chemical Science, Federal University, Wukari Nigeria \\ ${ }^{2}$ Chemistry Programme, Abubakar Tafawa Balewa University Bauchi, Nigeria \\ ${ }^{3}$ Department of Chemical Science, Cross River University of Technology Calabar, Nigeria
}

*Corresponding Author: Ushie O.A, Department of Chemical Science, Federal University, Wukari Nigeria. Email: afiushie@yahoo.com

\begin{abstract}
Cold extraction method was used extract the crude solvent extracts of leaf of Chrysophyllum albidum. The structural elucidation by spectroscopic methods $\left({ }^{1} \mathrm{H}\right.$ and $\left.{ }^{13} \mathrm{C} N \mathrm{NM}\right)$ of a fraction of ethyl acetae extract of $C$. albidum yielded a new compound characterized as decyl heptadecanoate. A similar compound Decyl -8- hydroxyl heptadecanoate has also been isolated from Ziziphusmauritiana leaves and has been synthesized via utilization of microwave energy using available starting compounds.
\end{abstract}

\section{INTRODUCTION}

Historically, plants have provided a source of inspiration for novel drug compounds as plants derived medicines have made large contributions to human health and well-being [1]. According to the World Health Organization (WHO), nearly 20,000 medicinal plants exist in 91 countries including 12 mega biodiversity countries [2]. It is observed that in Nigeria, $70 \%$ to $80 \%$ of the populations rely on plants for their primary health care needs [3]. The research on medicinal plants is gradually gaining due to increasing number people relying on the use of different parts of these materials for various ailments [4]. Only a small fraction of the world's biodiversity has been explored for bioactivity to date.

Most of the claims are made by traditional medical practitioner themselves and may not have been exhaustively investigated scientifically [5]. For this reasons therefore, it could be argued that further research into this medicinal plant is needed. The leaves of Chrysophyllum albidum is used by the rural inhabitants and traditional medicine practitioners in Calabar municipality Government of Cross River State for the treatment of malaria, yellow fever, diarrhea, vaginal and dermatological infections. Few workers have revealed the presence of certain secondary metabolites in this plant (C. albidum) but to the best of my knowledge no specific chemical constituent has been isolated and reported to be responsible for these activities in this part of the world. From available literature there is no work which has been done on the plant Chrysophyllum albidum leaves, in Calabar Muncipality, Local Government Area, of Cross River State Nigeria. The present work is designed to carry out the characterization and identification of bioactive compounds from C. albidum leaf extracts.

\section{MATERIALS AND MeTHODS}

\subsection{Sample Collection and Preparation}

Chrysophyllum albidum leaves were collected from their natural habitat of plain sandy soil of coastal plain sands in Calabar Municipality $\left(04^{\circ} 15^{\circ} \mathrm{N} ; 08^{\circ} 25^{\circ} \mathrm{E}\right)$, Nigeria. The sample were air-dried for two weeks and then milled into fine powder using a milling machine.

\subsection{Method of Extraction}

The method of cold maceration was used in the extraction by serial exhaustive extraction method which involves successive extraction with solvents of increasing polarity from a non polar (hexane) to a more polar solvent (methanol) to ensure that a wide polarity range of compound could be extracted. The extracts of the leaves was prepared by soaking $100 \mathrm{~g}$ of each in $250 \mathrm{ml}$ hexane for four days with frequent agitation until soluble matter is dissolved.. The resulting mixture was filtered by gravity filtration and the filtrate was concentrated by evaporation using rotatory evaporator and weighed. The 
procedure was repeated on the residue using the following solvents: chloroform, ethyl acetate, acetone and methanol sequentially in order of polarity. The extracts were in a refrigerator under argon condition until required for testing.

\subsection{Isolation (Purification) of Active Components for the Antimicrobial Activities}

The procedures that were used for isolation and purification of the components were thin layer chromatography and column chromatography. Thin layer chromatography was performed by the method described by [6]. Mixture of solvents was used to develop the plates on which the various extracts were applied on. The solvents composition (hexane and chloroform) with a composition of 7:3 and 3:7. After development, the zones of the various coloured bands were outlined in pencil. The distances of different spots traveled from the initial point of the original spotting were measured. The solvent front distance that was marked was also measured.

The distance moved by the solvent from the base line was calculated as

$R f=\frac{\text { distance from the sample spot to the centre of the band }}{\text { distance travelled by the solvent front }}$

Column chromatography was performed on the various extracts by the method described by Pavia et al. 1996. The materials used for the packing of the column were wad of glass wool, silica gel and the solvent. Before the extracts were loaded into the column they were first filtered using cealite diatomic earth and the filtrate were loaded into the column as semi purified. The solvent used for the packing end elution depended on the extract which was determined by the thin layer chromatography that was performed. Fractions were collected at regular interval and each fraction was monitored by TLC analysis. The procedure was repeated on the other extracts with solvent mixture as indicated above used for the thin layer chromatography.

\subsection{Structural Elucidation}

The structural elucidation was done by spectroscopic methods (IR, ${ }^{1} \mathrm{HNMR}$, and ${ }^{13} \mathrm{CNMR}$ ). The spectroscopic measurements were done on the isolates from the ethyl acetate extracts of the leaf of chrysophyllum albidum. The spectroscopic measurements were infrared spectroscopy (IR) and nuclear magnetic resonance NMR measurements. Electronic absorption spectra were recorded on IR spectrometer and were recorded in $10 \mathrm{~nm}$ path cuvette. An infrared spectrophotometer model Brunker IFS $66 \mathrm{~V} / \mathrm{S}$ was used to record infra-red measurements. NMR spectra were obtained with a Brunker AVANCE $400\left(400 \mathrm{MH}_{\mathrm{z}}\right)$ Fourier transform NMR spectrometer with chemical shifts reported in parts per million (ppm) with respect to TMS.

\section{RESULT AND DISCUSSIONS}

\subsection{Result of the Qualitative TLC of the C. albidum Leaf Extracts}

Table 1 present the result of the qualitative TLC performed on the ethyl acetate crude extracts of leaf of Chrysophyllum albidum There two spots detected on the TLC plates which implies that there are two different components in each of the extracts. Result of the qualitative TLC of the isolated component of the C. albidum leaf extracts is presented in Table 2. The result shows one spot each which implies one compound in each of the extracts.

Table1.Result of Qualitative TLC of Leaf ethyl acetate extract of Chrsophyllum albidum

\begin{tabular}{|l|l|l|}
\hline Extracts & No. of Spots & $\mathbf{R}_{\mathbf{f}}$ \\
\hline & & \\
\hline LEAE & 1 & 0.766 \\
\hline & 2 & 0.432 \\
\hline
\end{tabular}

LEAE - Leaf ethyl acetate extract

Table2.Thin Layer Chromatography Result of the Purified Components of the Chrysophyllum albidum Leaf Ethyl acetate extract

\begin{tabular}{|l|l|}
\hline Fractions & $\mathbf{R}_{\mathbf{f}}$ values \\
\hline LEAEF & 0.766 \\
\hline
\end{tabular}

LEAEF- Leaves ethyl acetate fraction 


\subsection{Result of Structural Elucidation}

The result of structural elucidation by the structures were elucidated by spectroscopic methods (IR, UV on addition of shift reagents, ${ }^{1} \mathrm{H}$ NMR, ${ }^{13} \mathrm{C}$ and NMR) an the result are as follows;

\subsection{FTIR Spectra Data for Isolated Ethyl Acetate Fraction}

The FTIR spectrum displayed $\mathrm{C}=\mathrm{O}$ asymmetric stretching in Carbonyl (ester) at $1750, \mathrm{C}-\mathrm{H}$ assymetric stretching in $-\mathrm{CH}_{3}$ at $2925 \mathrm{~cm}^{-1}$, C-H stretching frequencies in $-\mathrm{CH}_{2-}$. It also displayed $\mathrm{C}-\mathrm{H}$ bending in $\mathrm{CH}_{3}$ at $1400 \mathrm{~cm}^{-1}$ and $\mathrm{C}-\mathrm{O}-\mathrm{C}$ in acetates at 1250. The FTIR analysis of isolated ethyl acetate component of $C$. albidum leaves extract is presented in Table 3 below.

\section{4. ${ }^{1} \mathrm{HNMR}$ and ${ }^{13} \mathrm{CNMR}$ Spectra Interpretation for Ethyl Acetae Fraction (EAF)}

In the ${ }^{1} \mathrm{HNMR}$ the signal at $\delta 0.85$ is due to methyl group. The $\delta$ at $1.25 \& 1.67$ are due to long chain methylene protons. The $\delta$ at 2.31 is due to the methylene group adjacent to a carbonyl group. The signal at $\delta 4.07$ is due to a methylene proton attached to the oxygen functional group. The result is presented in Table 4 below. The ${ }^{1}$ HNMR are confirmed by the ${ }^{13}$ CNMR spectral data. The signal $\delta$ at 174.07 indicates the presence of an ester carbonyl group. The signal $\delta$ at 14.13 suggests the presence of methyl group. The signal at $\delta 64.42$ shows the presence of a carbon under the oxygen function. The signals at $\delta 22.70,25.04,25.95,28.66,29.17,29.28,29.37,29.49,29.71,31.94,34.43$ are due to long chain methylene groups.

Table3. The FTIR Spectral Data and Interpretation of Isolated Ethyl Acetate Fraction

\begin{tabular}{|l|l|l|}
\hline Frequency range $\mathbf{~ c m ~}^{-1}$ & Vibrational mode & Remarks \\
\hline 1750 & C=O Stretching & Carbonyl (Ester) \\
\hline 2925 & C-H Asymmetric stretching & $-\mathrm{CH}_{3}$ \\
\hline 2900 & C-H Stretching frequencies & $-\mathrm{CH}_{2}-$ \\
\hline 1400 & C-H Bending & $-\mathrm{CH}_{2}-$ \\
\hline 1250 & C-O-C Stretching & Acetates \\
\hline
\end{tabular}

Table4. The ${ }^{13}$ CNMR and ${ }^{1}$ HNMR Spectral Data of Isolated Ethyl acetate Fraction

\begin{tabular}{|c|c|c|c|}
\hline C-Positions & Carbon type or group & Carbon Signal ( $\delta$ ) & Proton Signal ( $\delta$ ) \\
\hline C-1 & $\mathrm{CH}_{3}$ & 14.13 & $0.85 \mathrm{~s}$ \\
\hline $\mathrm{C}-2$ & $\mathrm{CH}_{2}$ & 22.70 & $1.43 \mathrm{~s}$ \\
\hline $\mathrm{C}-3$ & $\mathrm{CH}_{2}$ & 32.08 & $1.25 \mathrm{~s}$ \\
\hline $\mathrm{C}-4$ & $\mathrm{CH}_{2}$ & 29.85 & $1.25 \mathrm{~s}$ \\
\hline $\mathrm{C}-5$ & $\mathrm{CH}_{2}$ & 29.82 & $1.25 \mathrm{~s}$ \\
\hline $\mathrm{C}-6$ & $\mathrm{CH}_{2}$ & 29.82 & $1.25 \mathrm{~s}$ \\
\hline $\mathrm{C}-7$ & $\mathrm{CH}_{2}$ & 29.82 & $1.25 \mathrm{~s}$ \\
\hline $\mathrm{C}-8$ & $\mathrm{CH}_{2}$ & 29.82 & $1.25 \mathrm{~s}$ \\
\hline C-9 & $\mathrm{CH}_{2}$ & 29.85 & $1.67 \mathrm{~s}$ \\
\hline $\mathrm{C}-10$ & $\mathrm{CH}_{2}$ & 29.11 & 4.07 \\
\hline $\mathrm{C}-11$ & $\mathrm{C}-\mathrm{O}$ & 64.42 & - \\
\hline $\mathrm{C}-12$ & $\mathrm{C}=\mathrm{O}$ & 174.07 & - \\
\hline $\mathrm{C}-13$ & $\mathrm{CH}_{2}$ & 33.98 & $1.61 \mathrm{~m}$ \\
\hline $\mathrm{C}-14$ & $\mathrm{CH}_{2}$ & 25.84 & $2.31 \mathrm{~s}$ \\
\hline $\mathrm{C}-15$ & $\mathrm{CH}_{2}$ & 29.82 & $1.25 \mathrm{~s}$ \\
\hline $\mathrm{C}-16$ & $\mathrm{CH}_{2}$ & 29.82 & $1.25 \mathrm{~s}$ \\
\hline $\mathrm{C}-17$ & $\mathrm{CH}_{2}$ & 29.82 & $1.25 \mathrm{~s}$ \\
\hline $\mathrm{C}-18$ & $\mathrm{CH}_{2}$ & 29.82 & $1.25 \mathrm{~s}$ \\
\hline C-19 & $\mathrm{CH}_{2}$ & 29.82 & $1.25 \mathrm{~s}$ \\
\hline $\mathrm{C}-20$ & $\mathrm{CH}_{2}$ & 29.82 & $1.25 \mathrm{~s}$ \\
\hline $\mathrm{C}-21$ & $\mathrm{CH}_{2}$ & 29.82 & $1.25 \mathrm{~s}$ \\
\hline $\mathrm{C}-22$ & $\mathrm{CH}_{2}$ & 29.82 & $1.25 \mathrm{~s}$ \\
\hline $\mathrm{C}-23$ & $\mathrm{CH}_{2}$ & 29.82 & $1.25 \mathrm{~s}$ \\
\hline $\mathrm{C}-24$ & $\mathrm{CH}_{2}$ & 29.82 & $1.25 \mathrm{~s}$ \\
\hline $\mathrm{C}-25$ & $\mathrm{CH}_{2}$ & $32 . .08$ & $1.25 \mathrm{~s}$ \\
\hline $\mathrm{C}-26$ & $\mathrm{CH}_{2}$ & 22.85 & $1.43 \mathrm{~s}$ \\
\hline $\mathrm{C}-27$ & $\mathrm{CH}_{3}$ & 14.13 & $0.85 \mathrm{~s}$ \\
\hline
\end{tabular}




\section{DISCUSSION}

TLC provides an easy and rapid way to study plants extract profiles and partially identify compounds [7]. The TLC result of that the extract revealed two spots for the ranging from 0.429 to 0.768 . The TLC result for the methanol gave an $R_{f}$ of 0.766 . Nuclear magnetic resonance (NMR) is a spectroscopic method that is more important to organic chemists. The combination of Infrared (IR) and NMR data is often sufficient to determine the structure of an unknown molecule [8]. The structural elucidation was done by spectroscopic methods (IR, ${ }^{1} \mathrm{H}$ NMR and ${ }^{13} \mathrm{CNMR}$ ) and was carried on the purified extract. The results revealed one novel compound characterized decyl heptadecanoate IR, ${ }^{1} \mathrm{HNMR}$ and ${ }^{13} \mathrm{CNMR}$.

Decyl heptadecanoate is a purified component from the ethyl acetate extract. TLC and column chromatography were used for purification that was performed on the ethyl acetate extract. The IR spectra showed the presence of a carbonyl group by exhibiting an absorption band at $1734 \mathrm{~cm}^{-1}, \mathrm{C}-\mathrm{H}$ group by exhibiting absorption bands at 2918 (stretching frequency and at 1463 and $1384 \mathrm{~cm}^{-1}$ (bending frequencies) and C-O group by exhibiting a band at $1179 \mathrm{~cm}^{-1}$.

In the ${ }^{1} \mathrm{H}$-NMR the signal at $\delta 0.85$ is due to methyl group, the broad singlet at $\delta 1.25$ and the multiplet at 1.61 are due to long chain methylene protons. The multiplet at $\delta 2.37$ is due to the methylene group adjacent to a carbonyl group and the signal at $\delta 4.07$ is due to a methylene group under the oxygen function. The above assignments are confirmed by the ${ }^{13} \mathrm{C}$-NMR spectral data. The signal at $\delta 174.07$ indicates the presence of an ester carbonyl group. The signal at $\delta 14.13$ suggests the presence of methyl group. The signal at $\delta 64.42$ shows the presence of a carbon under the oxygen function. The remaining signals at $\delta 22.70,25.04,25.95,28.66,29.17,29.28,29.37,29.49,29.71$, $31.94,34.43$ are due to long chain methylene groups. Based on the above data the compound may be assigned as a long chain fatty ester decyl heptadecanoate. A similar compound Decyl -8- hydroxyl heptadecanoate has also been isolated from Ziziphus mauritiana leaves [9] and has been synthesized via utilization of microwave energy using available starting compounds [10].

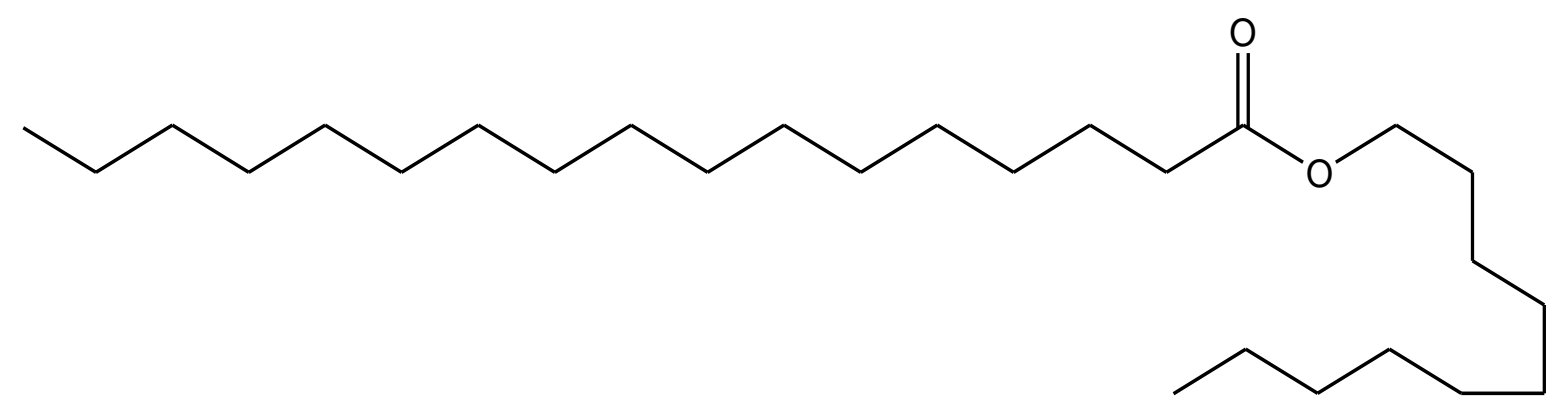

Decyl heptadecanoate

\section{CONCLuSion}

It can be concluded that the structural elucidation by spectroscopic methods (IR, ${ }^{1} \mathrm{H}$ NMR, ${ }^{13} \mathrm{C}$ and NMR) of ethyl acetate extract of $C$. albidum yielded one new compound characterized as decyl heptadecanoate using IR, ${ }^{1} \mathrm{HNMR}$ and ${ }^{13} \mathrm{CNMR}$.

\section{REFERENCES}

[1] Achan, M., Ndaalio, G., Weevers, H. \& Sawhey, A. (1980). Studies on Medicinal plants for antibacterial activity. Plant medica (Suppl) 91-97

[2] Sasidharan, S, Y., Chen, D., Saravanan, K. M. Sundram, \& Yoga, L. (2010). Extraction, Isolation and Characterization of Bioactive Compounds from Plants' Extracts African Journal of Traditional Complementary Alternative Medicine. 8(1): 1-10.

[3] Mathew, A.O. (1996). Conservation of useful plants in Nigeria, proceedings of national workshop on Medicinal plants, Abuja Horticultural Society, National Park Board and towers, Nigeria, 33-43.

[4] Adeshina, G. O., Onujagbe \& Onaolapo, J. (2010). Comparative antibacterial studies on the root, stem bark and leaf extracts of Parkia Clappertoniana. The Internet Journal of Alternative Medicine. 8(2), 1-7

[5] Soforowa, A. (1982): Medicinal plants and traditional medicine in Africa 11: 128. 142, 146. Pitman Press Ltd.

[6] Pavia, L.K. (1976). A contemporary approach, Introduction to organic laboratory techniques, N.B. Saunders company Canada, 46, 50, 358, 599 - 605. 
[7] Vázquez, L. H., Javier, P. \& Arturo, N. (2012). The Pentacyclic Triterpenes -amyrins: A Review of Sources and Biological Activities, Phytochemicals - A Global Perspective of Their Role in Nutrition and Health, Dr Venketeshwer Rao (Ed.), InTech, Available from: http://www.intechopen.com/books/ phytochemicals-a-global-perspective-of-their-role-in-nutrition and health/the-pentacyclic-triterpenesamyrins-a-review of-sources-and-biological-activities. Downloaded 12/08/2013

[8] Lampman, G. A., Pavia, D. L., Kriz, G. S \& Vyvyan, J. R (2012). Spectroscopy. International Edition $4^{\text {th }}$ edition. Cengage Learning Media Private Limited. 4,8, F.I.E Patparganji, Delhi, India.

[9] Agarwal, S. K., Singh, S. S., Verma, S \& Kumar, S. (2000). Two new compounds from leaves of Zizipusmauritiana. Indian Journal of Chemistry 39B, 872-874

[10] Singh, S. A., M.L, Jasvinder Singh (2010). Total synthesis of three natural products: Decyl-8- hydroxy heptadecanoate, Undecyl hexadecanoate and 2,3-dihydroxypropyl hexadecanoate. India Journal of Chemistry 49:1648-1652

Citation: O. Ushie et al., "Decyl Heptadecanoate Detected in Ethyl Acetae Leaf Extract of Chrysophyllum albidium", International Journal of Medicinal Plants and Natural Products (IJMPNP), vol. 4, no. 2, pp. 8-12, 2018. http://dx.doi.org/10.20431/2454-7999.0402002

Copyright: (C) 2018 Authors. This is an open-access article distributed under the terms of the Creative Commons Attribution License, which permits unrestricted use, distribution, and reproduction in any medium, provided the original author and source are credited. 